\title{
Kualitas Layanan Bidang Penempatan Kerja dalam Meningkatkan Kepuasan Masyarakat pada Dinas Tenaga Kerja Kota Banjarmasin
}

\author{
Khairunnisa \\ STIE Pancasetia Banjarmasin \\ Email : khairunisa@gmail.com
}

\begin{abstract}
Problem Formulation in this research are indicates that How quality of service bidang Penempatan Tenaga Kerja on Dinas Tenaga Kerja Kota Banjarmasin consist of tangible, reliability, responsiveness, assurance and empathy up grade social satisfaction. Kind data concists of quantitative data and qualitative data. Source data consist of prymary data and secondary data. Draft this research according to method using survey research is collection of data only done for in part of population. Population and sample this research amount 150 respondents. Technique collected data among them Field research are questionnairy, interview, observation, documentation and library research. Technique data analysis be explained in descriptive with quantitative is statistics method to used for describe of data collected.
\end{abstract}

Key Word : discipline, value achievement

Abstrak

Rumusan masalah pada penelitian ini menunjukkan bahwa Bagaimana kualitas layanan bidang Penempatan Tenaga Kerja pada Dinas Tenaga Kerja Kota Banjarmasin yang terdiri dari : tangible, reliability, responsiveness, assurance dan empati dalam meningkatkan kepuasan masyarakat. Jenis data terdiri dari data kuantitatif dan data kualitatif. Sumber data terdiri dari data primer dan data sekunder. Rancangan penelitian ini menurut metodenya menggunakan penelitian survey yaitu pengumpulan data hanya dilakukan pada sebagian dari populasi.Populasi dan sampel penelitian ini berjumlah 150 responden. Teknik pengumpulan data diantaranya penelitian lapangan yaitu kuesioner, observasi, dokumentasi dan peneliian kepustakaan. Teknik analisis data diuraikan secara deskriptif dengan metode kuantitatif yaitu metode-metode statistika yang digunakan untuk menggambarkan data yang dikumpulkan.

Kata Kunci : Kualitas layanan, Kepuasan masyarakat

(C) 2021 Jurnal Riset Inspirasi Manajemen dan Kewirausahaan

\section{PENDAHULUAN}

Setiap pelayanan akan menghasilkan beragam penilaian yang datangnya dari pihak yang dilayani. Pelayanan yang baik tentunya akan memberikan penilaian yang baik pula dari masyarakat, akan tetapi apabila pelayanan yang diberikan tidak memberikan kepuasan, misalnya masyarakat telah mengeluarkan sejumlah biaya untuk pelayanan tetapi imbalan yang diterimanya tidak seimbang, maka akan menimbulkan kekecewaan dan bisa memperburuk citra instansi sebagai pemberi layanan.

Dinas Tenaga Kerja Kota Banjarmasin adalah unit kerja yang bergerak di bidang pelayanan yang berkaitan dengan bidang ketenagakerjaan. Kegiatan dalam bidang ketenagakerjaan meliputi produktivitas, penempatan, pembinaan hubungan industrial dan penempatan tenaga kerja.
Dinas Tenaga Kerja Kota Banjarmasin merupakan SKPD yang memiliki kewenangan di bidang tenaga kerja. Bidang tenaga kerja mencakup pekerja, pengusaha dan lembaga pelatihan swasta.

Seiring berkembangnya masyarakat, tingkat kepedulian dari masyarakat terhadap masalah ketenagakerjaan cukup baik. Perusahaan yang semakin banyak menyerap tenaga kerja, sedikit banyaknya mengurangi jumlah pengangguran di Kota Banjarmasin. Berkembangnya Lembaga Pelatihan Kerja (LPK) Swasta dengan berbagai tawaran keahlian penjurusan juga membantu dalam mempersiapkan tenaga kerja yang siap pakai.

Berdasarkan hal ini, kualitas pelayanan pada kantor Dinas Tenaga Kerja ditujukan kepada masyarakat yang ingin membuat kartu tanda pencari kerja, memberikan informasi mengenai lowongan pekerjaan bagi pencari kerja, memberikan informasi kepada perusahaan tentang pencari kerja yang mereka butuhkan. Mendata 
lowongan ke perusahaan-perusahaan, mencari data penempatan maupun mendata pencari kerja yang sudah diterima pada perusahaan itu, mendata BKK (Bursa Kerja Khusus) ke sekolah-sekolah SMK kejuruan maupun perguruan tinggi, memberikan rekomendasi kepada calon TKI yang ingin bekerja keluar negeri, mendata TKA (Tenaga Kerja Asing) yang bekerja di Banjarmasin. Memberikan ijin kepada tenaga kerja asing untuk bekerja diwilayah kota Banjarmasin (INTA /Ijin Masuk Tenaga Kerja Asing), mendata perusahaan yang masih ada TKA nya, memberikan bantuan modal usaha kepada masyarakat berupa perlengakpan yang mereka butuhkan untuk membuka usaha.

\section{KAJIAN LITERATUR}

\section{Pengertian Kualitas}

Kualitas adalah Kesesuaian dengan persyaratan, kecocokan pada pemakaian, perbaikan atau penyempurnaan, berkesinambungan, bebas dari kerusakan atau cacat, pemenuhan kebutuhan konsumen baik sejak awal maupun setiap saat, melakukan segala sesuatu dengan benar sejak awal dan sesuatu dilakukan untuk membahagiakan konsumen (Tjiptono, 2004 : 2).

\section{Pengertian Pelayanan}

Groonroos dalam Ratmiko, dkk (2006 : 2) menjelaskan bahwa pelayanan adalah usaha aktivitas atau serangkaian aktivitas yang bersifat tidak kasat mata (tidak dapat diraba) yang terjadi sebagai akibat adanya interaksi antara konsumen dengan karyawan atau hal-hal lain yang disediakan oleh perusahaan pemberi pelayanan yang dimaksudkan untuk memecahkan permasalahan konsumen.

\section{Pengertian Kualitas Pelayanan}

Menurut Crosby dalam Suryanto (2010 : 50) kualitas pelayanan adalah penyesuaian terhadap perincian-perincian, dimana kualitas ini dipandang sebagai derajat keunggulan yang ingin dicapai, dilakukannya rangka memenuhi kebutuhan pengguna jasa.

\section{Dimensi-Dimensi Kualitas Pelayanan}

Terdapat lima dimensi kualitas pelayanan menurut Parasuraman dalam Lupiyoadi (2006 : 182), diantaranya :

1. Tangibles, atau bukti fisik yaitu kemampuan perusahaan dalam menunjukan eksistensinya kepada pihak eksternal.

2. Reliability, atau kehandalan yaitu kemampuan perusahaan untuk memberikan pelayanan sesuai yang dijanjikan secara akurat dan terpercaya.

3. Responsiveness, atau ketanggapan yaitu suatu kemauan untuk membantu dan responsiveness, atau ketanggapan yaitu suatu kemauan untuk membantu dan penyampaian informasi yang jelas.

4. Assurance, atau jaminan dan kepastian yaitu pengetahuan, kesopansantunan assurance, atau jaminan dan kepastian yaitu pengetahuan kesopansantunan pelanggan kepada perusahaan.

5. Empathy, yaitu memberikan perhatian yang tulus dan bersifat individual atau empathy.

\section{Pengertian Kepuasan Masyarakat}

Kepuasan masyarakat adalah perasaan senang atau kecewa seseorang yang berasal dari perbandingan antara kesannya terhadap kinerja atau hasil suatu produk dengan harapannya (Kotler, $2005: 70$ ).

\section{Kerangka Berfikir}

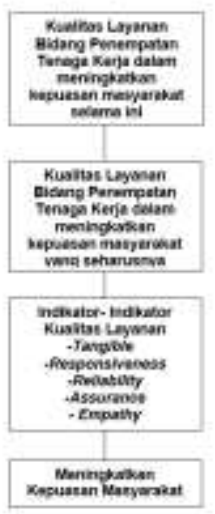

Gambar 1 Kerangka Berfikir

Sumber: Gambar diolah, 2021

\section{METODE PENELITIAN}

\section{Rancangan Penelitian}

Rancangan penelitian ini menurut metodenya menggunakan penelitian survei. Menurut Arikunto (2007 : 236) penelitian survei adalah "Pengumpulan data hanya dilakukan pada sebagian dari populasi".

\section{Jenis dan Sumber Data Penelitian}

Jenis data pada penenlitian ini terdiri dari :

1. Data Kuantitatif

Yaitu data yang berupa angka. Sesuai dengan bentuknya data kuantitatif dapat diolah atau dianalisis dengan menggunakan teknik perhitungan statistik.

2. Data Kualitatif

Yaitu data yang berupa pendapat, sehingga tidak berupa angka, tetapi berupa kata-kata atau kalimat. Data kualitatif dipeoleh dari berbagai teknik pengumpulan data, misalnya wawancara, observasi, dokumentasi yang telah dituangkan dalam bentuk transkrip. 


\section{Sumber Data}

Sumber data pada penelitian ini terdiri dari :

1. Data Primer

Yaitu data yang diperoleh langsung dari objek penelitian yaitu Dinas Tenaga Kerja Kota Banjarmasin, baik berupa hasil interview, melakukan observasi maupun data pendukung dokumentasi.

2. Data Sekunder

Data sekunder merupakan data pendukung yang diperoleh baik melalui dokumentasi dari objek penelitian, maupun diluar objek penelitian seperti, referensi buku, literatur, jurnal, internet.

\section{Populasi dan Sampel Penelitian}

1. Populasi

Populasi penelitian merupakan keseluruhan (universum) dari objek penelitian yang dapat berupa manusia, hewan, tumbuh-tumbuhan, udara, gejala, nilai, peristiwa, sikap hidup dan sebagainya (Bungin dalam Siregar, 2013 : 56). Besaran populasi pada penelitian ini sebesar 150 orang.

2. Sampel

Besaran sampel pada penelitian ini menggunakan quota sampling dengan merujuk kepada pendapat Siregar (61: 2013) yaitu metode penetapan sampel dengan menentukan quota terlebih dahulu pada masing-masing kelompok, sebelum quota masing-masing kelompok terpenuhi maka penelitian belum dianggap selesai.

Sehingga besaran sampel pada penelitian ini dengan menentukan jumlah quota sebesar 150 sampel.

\section{Teknik Pengumpulan Data}

Teknik pengumpulan data pada penelitian ini terbagi dua bagian, diantaranya :

1. Field research (Penelitian Lapangan)

a. Kuesioner

Yaitu menyebarkan angket kepada responden seputar pertanyaan tentang kualitas layanan Bidang Penempatan Tenaga Kerja pada Dinas Tenaga Kerja Kota Banjarmasin dalam meningkatkan kepuasan masyarakat.

b. Interview

Yaitu dilakukan dengan mewawancarai Pegawai Negeri Sipil pada Dinas Tenaga Kerja Kota Banjarmasin dengan tujuan untuk mendapatkan penjelasan kuantitatif dan kualitatif mengenai Sumber Daya Manusia dilingkungan Dinas Tenaga Kerja Kota Banjarmasin. Hasil interview akan digunakan untuk menambah informasi untuk hasil penganalisisan. c. Observasi

Yaitu dilakukan dengan cara melakukan pengamatan langsung ke objek penelitian yang berkaitan dengan pelaksanaan aktivitas pekerjaan pada Dinas Tenaga Kerja Kota Banjarmasin.

d. Dokumentasi

Yaitu data pendukung yang diperoleh dari objek penelitian yaitu berupa Renstra yang berisi mengenai sejarah singkat objek penelitian, visi dan misi, struktur organisasi, uraian tugas dan sebagainya.

2. Library research (Penelitian Kepustakaan)

Yaitu data pendukung yang digunakan sebagai landasan teori yang relevan dengan variabel yang digunakan maupun data penunjang yang lain berupa referensi buku, literatur, internet dan lain-lain.

\section{Teknik Analisis Data}

Teknik analisis data yang digunakan adalah analisis deskriptif kuantitatif yang bertujuan untuk menjelaskan kondisi yang terjadi sebenarnya secara konkrit dan nyata serta mengklasifikasikan data dari hasil penelitian.

\section{HASIL PENELITIAN DAN PEMBAHASAN}

\section{Pembahasan}

Berdasarkan hasil penyebaran kuesioner, diperoleh pernyataan responden mengenai beberapa variabel kualitas pelayanan dan kepuasan masyarakat sebagai berikut:

1. Variabel Tangible/ Bukti Fisik

Variabel tangible $\left(\mathrm{X}_{1}\right)$ memiliki tiga item pernyataan yang dapat dilihat pada tabel 1 berikut ini:

Tabel 1 Distribusi Variabel tangible $\left(\mathrm{X}_{1}\right)$

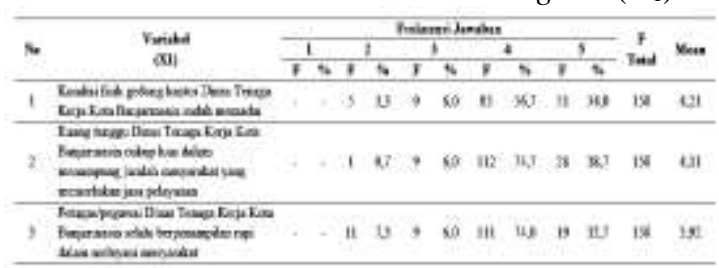

Sumber: Data di olah

Berdasarkan hasil tabulasi frekuensi variabel tangible $\left(\mathrm{X}_{1}\right)$ dapat ditarik kesimpulan bahwa secara umum responden sangatlah mempertimbangkan variabel tangible $\left(\mathrm{X}_{1}\right)$ khususnya pada item $\mathrm{X}_{1} .1$ yang menyatakan 
bahwa kondisi fisik gedung kantor Dinas Tenaga Kerja Kota Banjarmasin sudah memadai. Hal tersebut menunjukkan bahwa variabel tangible $\left(\mathrm{X}_{1}\right)$ mampu memberikan kepuasan masyarakat pada Kantor Dinas Tenaga Kerja Kota Banjarmasin.

2. Variabel Reliability/Kehandalan $\left(\mathrm{X}_{2}\right)$ Variabel reliability $\left(\mathrm{X}_{2}\right)$ memiliki tiga item pernyataan yang dapat dilihat pada tabel 2 berikut ini:

Tabel 2 Distribusi Variabel Reliability $\left(\mathrm{X}_{2}\right)$

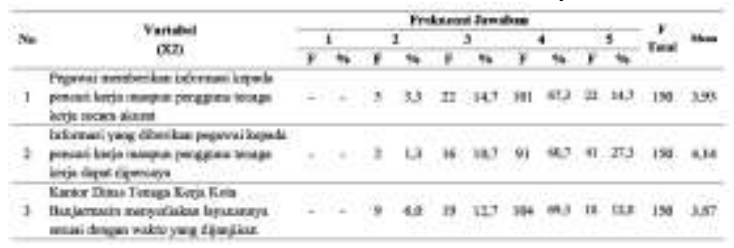

Sumber: Data diolah

Berdasarkan hasil tabulasi frekuensi variabel reliability $\left(\mathrm{X}_{2}\right)$ dapat ditarik kesimpulan bahwa secara umum responden sangatlah mempertimbangkan variabel reliability $\left(\mathrm{X}_{2}\right)$ khususnya pada item $\mathrm{X}_{2} .2$ yang menyatakan bahwa informasi yang diberikan pegawai kepada pencari kerja maupun pengguna tenaga kerja dapat dipercaya. Hal tersebut menunjukkan bahwa variabel reliability (X2) mampu memberikan kepuasan masyarakat pada Kantor Dinas Tenaga Kerja Kota Banjarmasin.

3. Variabel Responsiveness/Daya Tanggap (X3) Variabel responsiveness $\left(\mathrm{X}_{3}\right)$ memiliki tiga item pernyataan yang dapat dilihat pada tabel 3 berikut ini:

Tabel 3 Distribusi Variabel Reliability $\left(\mathrm{X}_{2}\right)$

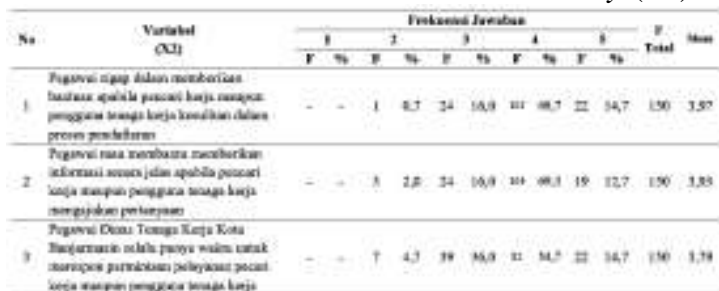

Sumber: Data diolah

Berdasarkan hasil tabulasi frekuensi variabel responsiveness $\left(\mathrm{X}_{3}\right)$ dapat ditarik kesimpulan bahwa secara umum responden sangatlah mempertimbangkan variabel responsiveness $\left(\mathrm{X}_{3}\right)$ khususnya pada item $\mathrm{X}_{3} .1$ yang menyatakan bahwa pegawai sigap dalam memberikan bantuan apabila pencari kerja maupun pengguna tenaga kerja kesulitan dalam proses pendaftaran. Hal tersebut menunjukkan bahwa variabel responsiveness $\left(\mathrm{X}_{3}\right)$ mampu memberikan kepuasan masyarakat pada Kantor Dinas Tenaga Kerja Kota Banjarmasin.

4. Variabel Assurance/Jaminan $\left(\mathrm{X}_{4}\right)$
Variabel assurance $\left(\mathrm{X}_{4}\right)$ memiliki tiga item pernyataan yang dapat dilihat pada tabel 4 berikut ini:

Tabel 4 Distribusi Variabel Assurance $\left(\mathrm{X}_{4}\right)$

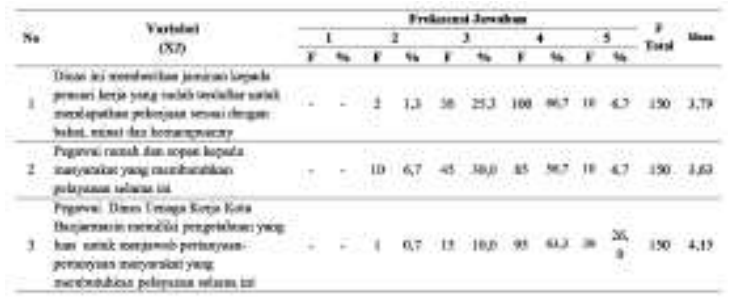

Sumber: Data diolah

Berdasarkan hasil tabulasi frekuensi variabel assurance $\left(\mathrm{X}_{4}\right)$ dapat ditarik kesimpulan bahwa secara umum responden sangatlah mempertimbangkan variabel assurance $\left(\mathrm{X}_{4}\right)$ khususnya pada item $\mathrm{X}_{4.3}$ yang menyatakan bahwa pegawai Dinas Tenaga Kerja Kota Banjarmasin memiliki pengetahuan yang luas untuk menjawab pertanyaan-pertanyaan masyarakat yang membutuhkan pelayanan selama ini. Hal tersebut menunjukkan bahwa variabel assurance (X4) mampu memberikan kepuasan masyarakat pada Kantor Dinas Tenaga Kerja Kota Banjarmasin.

5. Variabel Empathy/ Perhatian $\left(\mathrm{X}_{5}\right)$

Variabel empathy $\left(\mathrm{X}_{5}\right)$ memiliki tiga item pernyataan yang dapat dilihat pada tabel 5 berikut ini:

Tabel 5 Distribusi Variabel Empathy $\left(\mathrm{X}_{4}\right)$

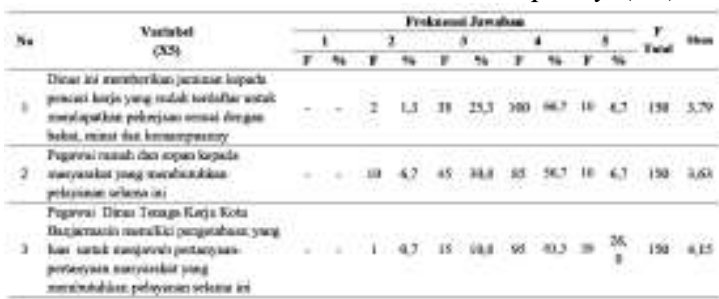

Sumber: Data diolah

Berdasarkan hasil tabulasi frekuensi variabel empathy $\left(\mathrm{X}_{5}\right)$ dapat ditarik kesimpulan bahwa secara umum responden sangatlah mempertimbangkan variabel empathy $\left(\mathrm{X}_{5}\right)$ khususnya pada item $\mathrm{X}_{5} .2$ yang menyatakan bahwa pegawai Dinas Tenaga Kerja Kota Banjarmasin memiliki keperdulian terhadap pencari kerja dalam mencari informasi tentang lowongan kerja. Hal tersebut menunjukkan bahwa variabel empathy $\left(\mathrm{X}_{5}\right)$ mampu memberikan kepuasan masyarakat pada Kantor Dinas Tenaga Kerja Kota Banjarmasin.

6. Variabel Kepuuasan Masyarakat

Variabel kepuasan masyarakat (Y) memiliki tiga item pernyataan yang dapat dilihat pada tabel 6 berikut ini: 


\begin{tabular}{l}
\hline \hline Tabel 6 Distribusi Kepuasan Masyarakat \\
\hline Sumber: Data diolah. \\
Dari hasil distribusi frekuensi mengenai \\
variabel kepuasan masyarakat (Y) dapat \\
disimpulkan bahwa secara umum \\
responden menanggapi secara positif \\
terhadap kepuasan masyarakat. Hal ini \\
dapat ditunjukkan dengan pernyataan pada \\
item Y ${ }_{1.3}$ mengenai pelayanan yang \\
diberikan Kantor Dinas Tenaga Kerja Kota \\
Banjarmasin selama ini sudah memberikan \\
kepuasan bagi masyarakat.
\end{tabular}

\section{PENUTUP}

\section{Kesimpulan}

Kesimpulan pada penelitian ini, sebagai berikut :

1. Kondisi fisik gedung kantor Dinas Tenaga Kerja Kota Banjarmasin sudah memadai. Hal tersebut menunjukkan bahwa variabel tangible $\left(\mathrm{X}_{1}\right)$ mampu memberikan kepuasan masyarakat pada Kantor Dinas Tenaga Kerja Kota Banjarmasin.

2. Informasi yang diberikan pegawai kepada pencari kerja maupun pengguna tenaga kerja dapat dipercaya. Hal tersebut menunjukkan bahwa variabel reliability $\left(\mathrm{X}_{2}\right)$ mampu memberikan kepuasan masyarakat pada Kantor Dinas Tenaga Kerja Kota Banjarmasin.

3. Pegawai sigap dalam memberikan bantuan apabila pencari kerja maupun pengguna tenaga kerja kesulitan dalam proses pendaftaran. Hal tersebut menunjukkan bahwa variabel responsiveness $\left(\mathrm{X}_{3}\right)$ mampu memberikan kepuasan masyarakat pada Kantor Dinas Tenaga Kerja Kota Banjarmasin.

4. Pegawai Dinas Tenaga Kerja Kota Banjarmasin memiliki pengetahuan yang luas untuk menjawab pertanyaanpertanyaan masyarakat yang membutuhkan pelayanan selama ini. Hal tersebut menunjukkan bahwa variabel assurance $\left(\mathrm{X}_{4}\right)$ mampu memberikan kepuasan masyarakat pada Kantor Dinas Tenaga Kerja Kota Banjarmasin.

5. Pegawai Dinas Tenaga Kerja Kota Banjarmasin memiliki keperdulian terhadap pencari kerja dalam mencari informasi tentang lowongan kerja. Hal tersebut menunjukkan bahwa variabel empathy $\left(\mathrm{X}_{5}\right)$ mampu memberikan kepuasan masyarakat pada Kantor Dinas Tenaga Kerja Kota Banjarmasin.

6. Secara umum responden menanggapi secara positif terhadap kepuasan masyarakat. Hal ini dapat ditunjukkan dengan pernyataan pada item $\mathrm{Y}_{1.3}$ mengenai pelayanan yang diberikan Kantor Dinas Tenaga Kerja Kota Banjarmasin selama ini sudah memberikan kepuasan bagi masyarakat.

\section{Saran}

Berdasarkan hasil kesimpulan tersebut diatas, maka dapat diidentifikasi apa saja yang perlu dilakukan Kantor Dinas Tenaga Kerja Kota Banjarmasin agar dapat meningkatkan kepuasan masyarakat, diantaranya :

1. Kantor Dinas Tenaga Kerja Kota Banjarmasin hendaknya memperhatikan variabel kualitas pelayanan masyarakat yang terdiri dari tangible, reliability, responsiveness, assurance, dan empathy secara menyeluruh, karena variabel ini mampu meningkatkan kepuasan masyarakat.

2. Kantor Dinas Tenaga Kerja Kota Banjarmasin hendaknya memperhatikan variabel kualitas pelayanan secara individual seperti;

a. Tangibles, yakni penilaian mencakup kondisi fisik, peralatan serta penampilan pegawai dalam memberikan pelayanan. Cara yang bisa dilakukan adalah dengan menyediaan alat-alat modern seperti ruang tunggu yang presentatif, pegawai yang profesional, menyediakan seragam pegawai yang lebih menarik, dan menyediakan sarana informasi (brosur, informasiinformasi layanan) yang lebih baik.

b. Reliability, yakni mampu memberikan pelayanan yang dijanjikan dengan segera dan akurat serta memuaskan. Agar semua itu bisa tercapai instansi perlu meningkatkan pengetahuan pegawai dengan mengadakan pelatihan dan pendidikan. Peningkatan terhadap kemampuan dan pengetahuan pegawai perlu diperioritaskan dan perlu dijadikan agenda utama, misalnya membuat jadwal pelatihan dan pendidikan.

c. Responsiveness, yakni sikap tanggap dan peduli dalam memberikan pelayanan kepada masyarakat. Hal ini bisa dilakukan dengan menumbuhkan rasa memiliki institusi bagi pegawai sehingga menciptakan pegawai yang lebih mengutamakan kedisplinan, berkomitmen yang berorientasi pada kepuasan masyarakat, mempunyai rasa kesetiakawanan antar pegawai agar dapat 
saling mendukung dalam memberikan pelayanan kepada masyarakat.

d. Assurance, yakni kemampuan memberikan kepastian dan jaminan dalam memberikan pelayanan untuk masyarakat. Hal ini bisa dilakukan dengan mengajak semua pegawai mengadakan meeting setiap minggu untuk menyamakan persepsi terhadap pemberian pelayanan kepada masyarakat agar pelayanan yang diberikan sesuai dengan aturan dan prosedur yang berlaku.

e. Empathy, yakni memberikan informasi terbaru dalam pelayanan, kepedulian untuk memahami keinginan dan kebutuhan masyarakat. Hal ini bisa dilakukan dengan melakukan pertemuan dengan masyarakat agar dapat menciptakan rasa kekeluargaan. Pertemuan itu bisa dilakukan pada saat masyarakat melakukan memerlukan pelayanan di kantor dan memberikan penjelasan tentang prosedur pelayanan yang ramah dan sopan santun.

\section{DAFTAR PUSTAKA}

Arikunto, Suharsimi, 2007, Manajemen Penelitian, Penerbit Rineka Cipta, Jakarta.

Kotler, Philip, 2005, Marketing Managemen : Analysis, Planning, Implementation, Sun Contol, Nith Edition, Pentice Hall, Inc Engleword Cliffs, New Jersey.

Rangkuti, Freddy, 2017, Measuring Customer Satisfaction, Cetakan ke tiga, PT. Gramedia Pustaka Utama, Jakarta.
Lupiyoadi, Rambat, 2006, Manajemen Pemasaran Jasa, Salemba Empat, Jakarta.

Rarin, Faizal Maulidhany, 2012, Analisis Kepuasan Pelanggan terhadap Pelayanan Pasien Rawat Jalan di Rumah Sakit Islam Hidayatullah Yogyakarta, Kindai, Vol 8, No : 2, Hal 112-202, April-Juni 2012, ISSN $1858-022 \mathrm{X}$.

Ratminto, dkk, 2006, Manajemen Pelayanan : Pengembangan Model Konseptual Penerapan Citizen Carter dan Standar Pelayanan Minimal, Pustaka Pelajar, Yogyakarta.

Siregar, Sofian, Statistik Parametrik untuk Penelitian Kuantitatif, PT Bumi Aksara, Jakarta.

Suryanto, 2010, Hubungan Kinerja Pegawai dengan Kualitas Pelayanan Masyaakat pada Kanto Kecamatan Matapura Kota, JURIAD, Vol. 9, No : 1, Hal. 001 - 108, ISSN 0216 - 4744.

Tjiptono, Fandy, 2004, Manajemen Pelayanan Jasa, Penerbit Andi, Yogyakarta.

\section{Profil Penulis}

Khairunnisa, S.E., M.M. Dosen STIE Pancasetia Banjarmsin

Jl. Ahmad Yani Km. 5,5 Kuripan, Pemurus Dalam, Kec. Banjarmasin Tim., Kota Banjarmasin, Kalimantan Selatan 70248 